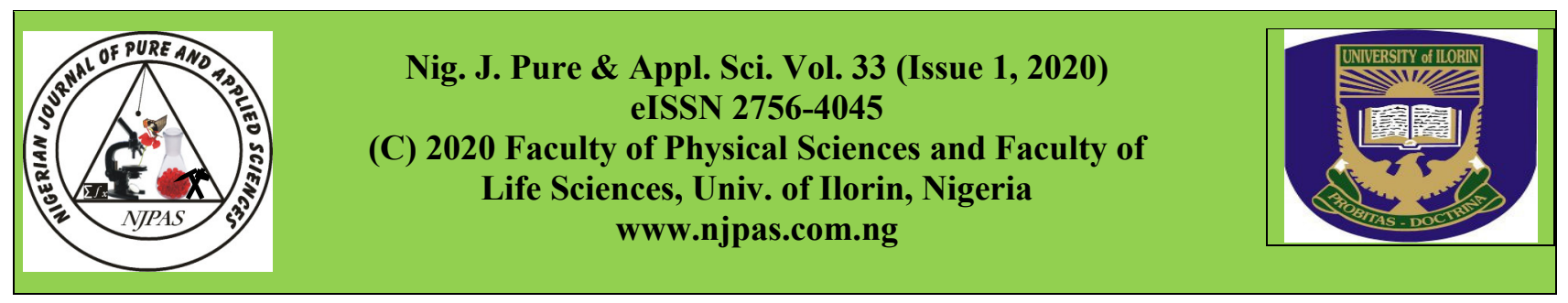

doi: http://dx.doi.org/10.48198/NJPAS/19.B15

\title{
DESIGN AND CONSTRUCTION OF A LOW-COST 30KV VARIABLE DC POWER SUPPLY UNIT
}

\author{
${ }^{1}$ Bolarinwa, H.S., ${ }^{1,2}$ Fajingbesi, F.E., ${ }^{1}$ Yusuf, A., ${ }^{1}$ Animasahun, L. O. ${ }^{1}$ Babatunde, Y. O. \\ ${ }^{1}$ Department of Physics Electronics and Earth Sciences, Fountain University Osogbo, Nigeria \\ ${ }^{2}$ Department of Electrical and Computer Engineering, Kuliyyah of Engineering Kuala Lumpur, Malaysia
}

\section{ABSTRACT}

A high voltage power supply is a key component in the advancement of science and technology. Application of high voltage power supply requires careful attention to critical variables such as voltage ripple, long and shortterm stability, repeatability and accuracy. These are important factors in the consideration of reliable scientific data. This paper presents the design of a low-cost high voltage power supply from the off-the-shelf electronics components to meet the high-end requirement of high voltage power supply. A $30 \mathrm{kV}, 63.8 \mathrm{~mA}$ maximum power supply was constructed at the Fountain University electronics workshop. This high voltage directs current (HVDC) power supply was built around three basic compartments that include an adjustable low voltage power supply (LVPS), a high frequency oscillator, and a line output transformer (LOPT) using flyback transformer, NE555timer, BU508D BJT, and other off-the-shelf components. The current-voltage relationship at the output of the constructed High Voltage Direct Current was found to be linear. This power source will serve any high DC voltage applications such as electrospinning. The constructed $30 \mathrm{kV}$ power supply has been tested in the electrospinning laboratory of the Center for Energy Research and Development (CERD) Obafemi Awolowo University (OAU) Ile-Ife. The unit successfully electrospun Zinc-Titaninm polymeric solution into fibers at about $8 \mathrm{kV}$. The importance of this fabricated device is its high reliability despite its low cost and capability to produce different magnitude of high voltage DC.

Keywords: Flyback, High voltage, Direct current, Power supply, Low cost

\section{Introduction}

High voltage refers to an output in the order of hundreds or thousands of volts (Garba, 2009). Most high-voltage supplies use a linear setup to produce an output voltage in this range. Some high voltage supplies provide analogue inputs that can be used to control the output voltage, effectively turning them into high-voltage amplifiers. There are several applications of high voltage direct current (D.C) power supply, in the field of electrical engineering and applied physics, such as electron microscopes, X-rays, electrostatic precipitators, particle accelerator in nuclear physics, dielectric testing, defibrillator in a medical lab, defense shield, stunt gun and electromagnetic pulse generator in the militia (Naidu and Kamaraju, 2013). Particularly, the principle of electrostatics

\section{Corresponding Author: Fajingbesi, F.E.}

Department of Physics Electronics and Earth Sciences, Fountain University Osogbo, Nigeria.

Department of Electrical and Computer Engineering, Kuliyyah of Engineering Kuala Lumpur, Malaysia Email: fawwazfajingbesi@yahoo.com babdulhakeem@gmail.com 
has found use in several applications such as electrospinning (Bolarinwa et al., 2017).

Basically, the principle of electrostatics is used in studying the effects produced by electric charges or electric fields especially where motion in materials Page | 3667 can be generated via the applications of electrostatics without any physical contact, to effect the separation of materials even down to their elemental level, which in turn facilitates the formation of homogeneous mixtures from combined materials used for scientific and practical purposes. (Scapellati, 1995). In most cases such as electrospinning, the required energy to give a required potential difference for the electrospinning process is derived through a high voltage DC source (Alayande et al., 2016). All applications of high voltage power require careful attention to critical variables such as voltage ripple, long and short-term stability, repeatability and accuracy. These are important factors in the consideration of reliable scientific data. Also, as analytical instrumentation finds its way into production process control, reliability and quality are equally important in the considerations for high voltage power supply specification. In the developing countries, experiments involving the use of sophisticated high voltages are limited due to cost of purchase; hence a design of such high voltages using the off-the-shelf, simple yet robust system is paramount. Although, there is no general rule of thumb in selecting an appropriate High Voltage Supply, some essential characteristics are consistent in a power supply design flow. Therefore, Figure 1 shows the three major categories of high voltage power supply in which most design are centered (Kuffel et al., 2000).

With advances in science and technology more and more device are invented that require stable power sources having voltage requirement in different range. Most electronic devices are designed to work on Direct Current (DC) source. They either step down or step up and convert the Alternating Current (AC) using rectifier circuits combined with other solid-state electronics in achieving this (Fajingbesi et al., 2017).

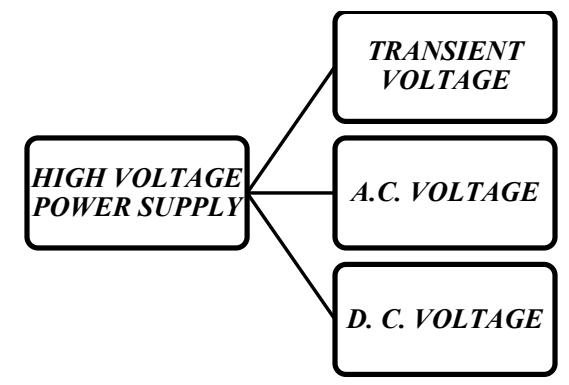

Figure 1: Categories of high voltage power supplies

Although a high voltage power supply can be achieved using various methods. The simplest and easiest among them is the multiplier circuit. A voltage multiplier is an electrical circuit that converts AC electrical power from a lower voltage to a higher DC voltage, typically by means of a network of capacitors and diodes (Forouzesh, et al., 2017).

The classification of such voltage multiplier depends on the ratio of output voltage to input voltage such as double, triple, quadruples and nplex. These circuits allow high voltages to be obtained using a much lower voltage AC source (Kuffel et al., 2000; Mazen et al., 2000; Zhang et al., 2002). The Voltage multiplier circuit which has the ratio of output voltage to input voltage depending on the number of stages is called Cockcroft-Walton voltage multiplier circuit which is used to develop high voltages in order of several KV (Dwivedi and Daigavane, 2011). An output voltage, from any stage, can be taken out through tapings. In this way Cockcroft-Walton voltage multiplier is isolated from the main line which result in the mitigation of switching surge voltages (Dwivedi and Daigavane, 2011).

Usually, a voltage multipliers circuit are designed using capacitors, diodes and half-wave rectifiers. For instance, a basic voltage doubler circuit will consists of two half-wave rectifiers, two capacitors, and two diodes (as in the Cockcroft Walton multiplier). To achieve a higher voltage range, - the 
included wave rectifiers can be configured in multiple ways. Also, a series or parallel configurations or a combination of both are fully explored. For parallel multipliers, each consecutive multiplication stage requires a higher voltage Page | 3668 rating, and lower capacitance. The maximum output voltage is then determined by the capacitor voltage rating. (Cyril, 1993; Yamamoto et al., 2000; Zhang et al., 2002 and Christophe, 2008)

Although this method is simple since it utilizes a high voltage transformer or an inverter at higher frequency, a high voltage capacitor and diode. The major drawback to such circuit is acquiring the high voltage components. However, this work have been able to achieve a higher voltage power supply system using a flyback (LOPT) transformer topology connected to a low voltage AC-DC power supply and an oscillator (stable) unit totally bypassing the difficulties and need associated to sourcing high end high voltage rating passive components.

\section{Materials and Methods}

This high voltage DC power supply is built around three basic compartments which include an adjustable low voltage power supply (LVPS), a high frequency oscillator for driving a line output transformer (LOPT) - commonly known as the fly back transformer - which boost the LVPS to attain High voltage. It should further be stated that this circuit's components were obtained - mostly as scraps from electronics appliance locally and simulated using NI Multisim 14 software. A block diagram of the high voltage power supply is shown in figure 2.

The circuit diagram in figure 3 shows all the components used in this work. The circuit was designed and simulated using an electronic workbench (NI Multisim 14). The circuit design was carried out at the Fountain University electronics workshop where the entire components were soldered onto printed circuit boards and carefully housed in a plastic casing with insulating wax to prevent internal arching and eventual collapse.

As shown in Figure 3, this circuit consists of simple step-down transformer (T1), connected to a bridge rectifier setup consisting of four power diode (D1). The outputs from D1 are tied to an electrolytic capacitor $(\mathrm{C} 1)$. Connected through a fuse (F1), the earlier stage has an attached indicator setup consisting of a resistor (R1) and a Light Emitting Diode (LED1). Also connected through this fuse is variable resistor attached to a power transistor (Q1) responsible for controlling the lower stag voltage output. For further safety and instant isolation between the lower voltage and the final higher output voltage section a switch (S1) is placed at this point. Further ahead is a simple RC filter (R3, C2) for smoothing of the lower voltage used to power the High frequency oscillator setup which is primarily centered on the NE555 Timer IC (U3). The output from this filter is tied to a fixed voltage regulator IC (U2) coupled with a capacitive ripple filter (C3) to power the 555 Timer IC. The operating frequency of the oscillator is controlled by varying the charge-discharge ratio of the capacitor (C4). The high frequency square wave output is thus tied to the base junction of the High power fast switching transistor (BU580D). A zener diode (D2), electrolytic capacitor (C6) and resistor (R7) are used to prevent backward coupling effect and reverse current from the flyback system during the transistor switching.

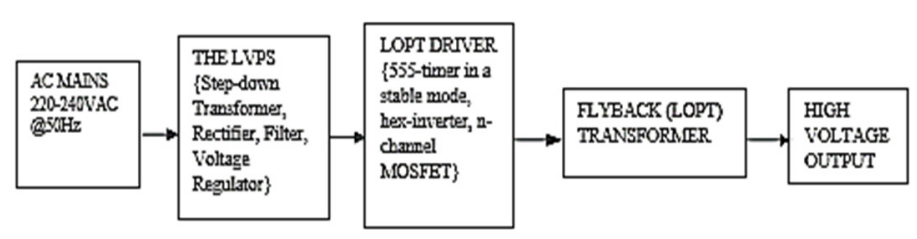

Figure 2: HVPS block diagram 


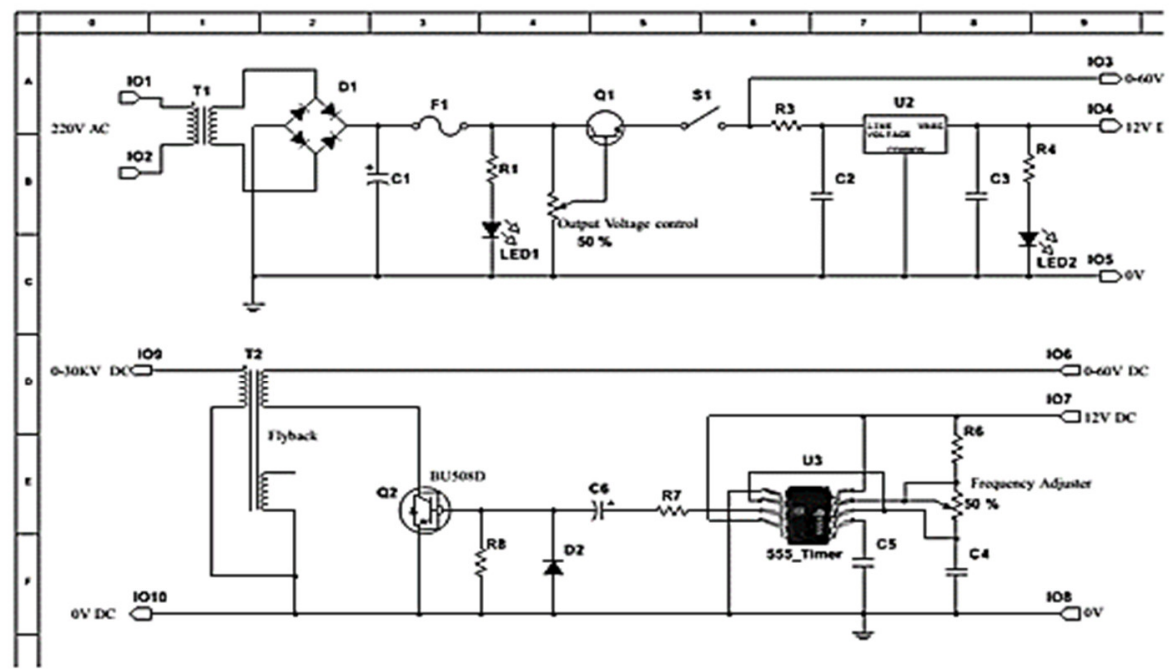

Figure 3: Circuit diagram of the high voltage power supply

\section{Results and Discussion}

The step-down transformer takes power from the AC mains (220VAC, $50 \mathrm{~Hz}$ ) and feeds it into the bridge rectifier. The bridge rectifier converts the alternating voltage from the transformer into varying DC output (Forouzesh et al., 2017). The variable DC outputs are smoothened by connecting a capacitor across the output, leaving a small amount of ripples. Then a voltage regulator is connected to this output to completely eliminate the ripples (Rashad et al., 2016). Two voltage regulators connected in parallel are employed in this circuit to give a stable output of $12 \mathrm{~V}$ and a regulated output, between 1-60 VDC. The variable resistor provide the means by which the output voltage is regulated, and this is the main voltage that is fed the flyback transformer input, and thus controls the final output high voltage (Haridas et al., 2016). Flyback transformer driver circuit was created to basically drive the flyback transformer. The main function of this circuit is to simulate a pulsed (square-wave), high frequency input to the flyback transformer, which then allows it to work (Hu et al., 2019). The square wave generated typically has a frequency between $25-100 \mathrm{kHz}$, in our case it was about $35 \mathrm{kHz}$, but the exact value can vary from one flyback transformer to another. A 555-timer, is connected in an astable mode to generate a square wave. The output of the 555-timer is coupled to the base of the transistor by a resistor connected in series with a capacitor. Periodic transitions of the output of the buffer from open, to a short where its sink current, allow it to switch the transistor on and off. The transistor being switched on and off is a high voltage bipolar junction transistor (BJT) BU508D specifically chosen because of its low collector-emitter resistance, so it heats up less $(\mathrm{Hu}, 2009)$. The transistor is connected in a heavy-side driver configuration, in which the primary of the flyback transformer is placed between the collector and the regulated input from the voltage regulator circuit. The output of this transistor is given in figure 4 and 5. As illustrated by the oscilloscope transient plot in Figure 4, we could notice the voltage measured is a square wave oscillating between the positive and the negative pole at a period of $10 \mu \mathrm{s}$. This shows the estimate switching states of the transistor and for every positive edge of the square wave the collector emitter junction is thus fully switched on as indicated by the transient plot on figure 5 . The 
second mini spike is attribute to the backward flow current during the flyback discharge phase.

The output current, voltage characteristics of the high voltage power supply at no load condition are Page | 3670 given in figure 6. Table 1 gives the important specification of the fully constructed high voltage power supply shown in Plate 1 below. On the front view of plate 1 , it consists of a digital voltage display indicator to highlight the current output operating voltage at load and no load conditions. There is also a power switch which controls weather power is delivered to the high voltage section of the device and the voltage adjust know to vary the output supply.

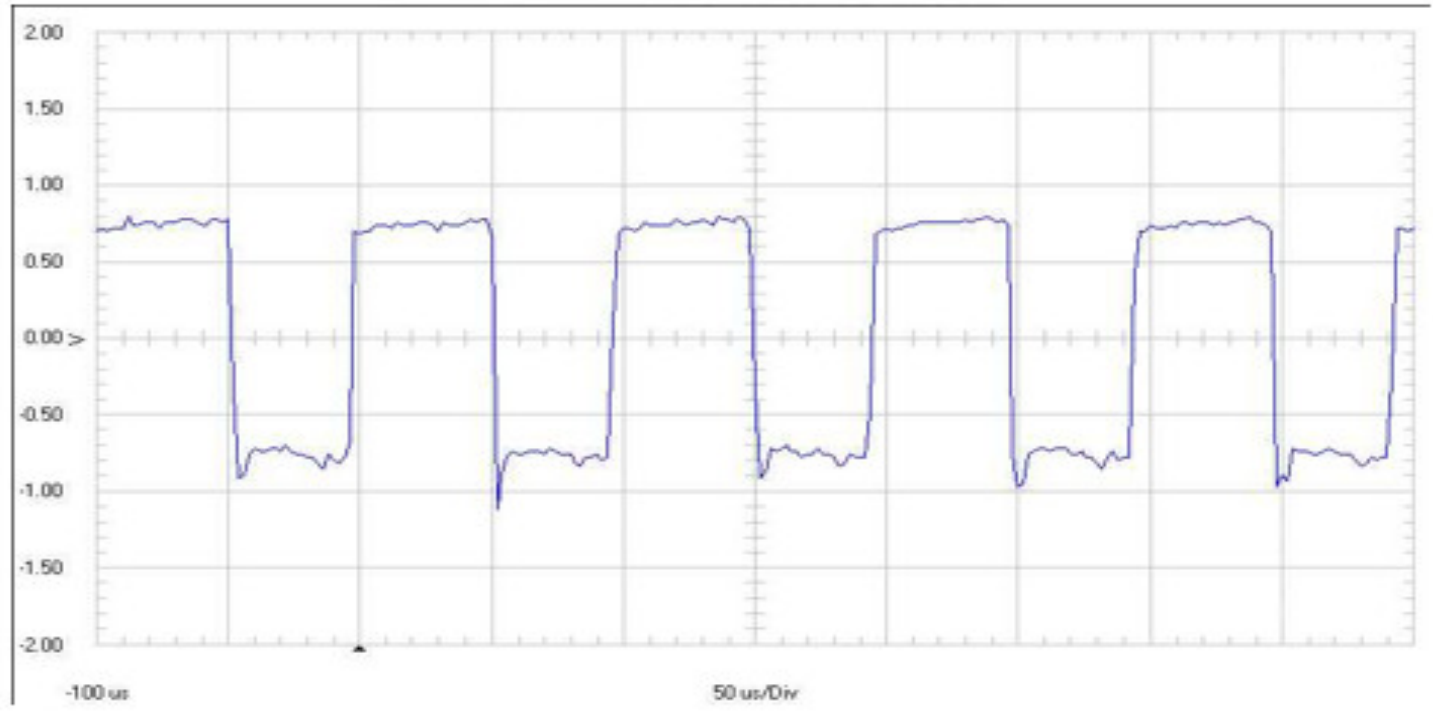

Figure 4: Voltage signal measured across the base -emitter junction of BU508D

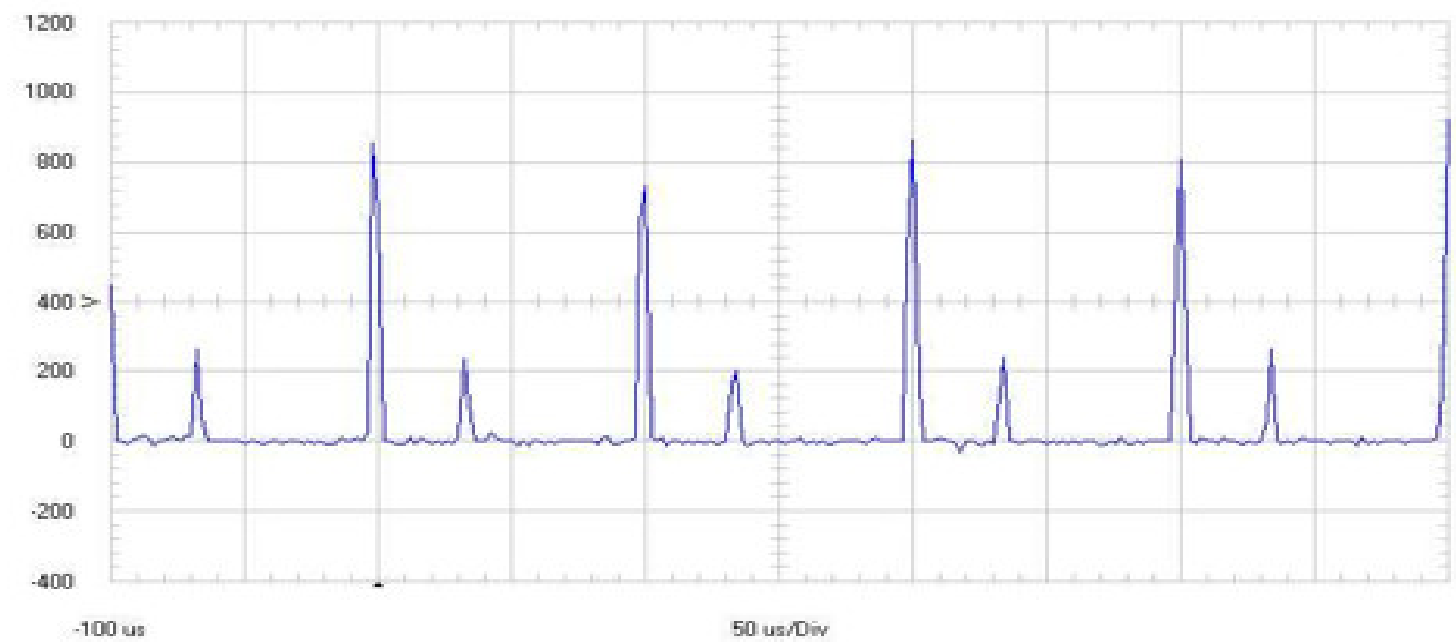

Figure 5: Voltage signal measured between the collector-emitter junctions of BU508D 


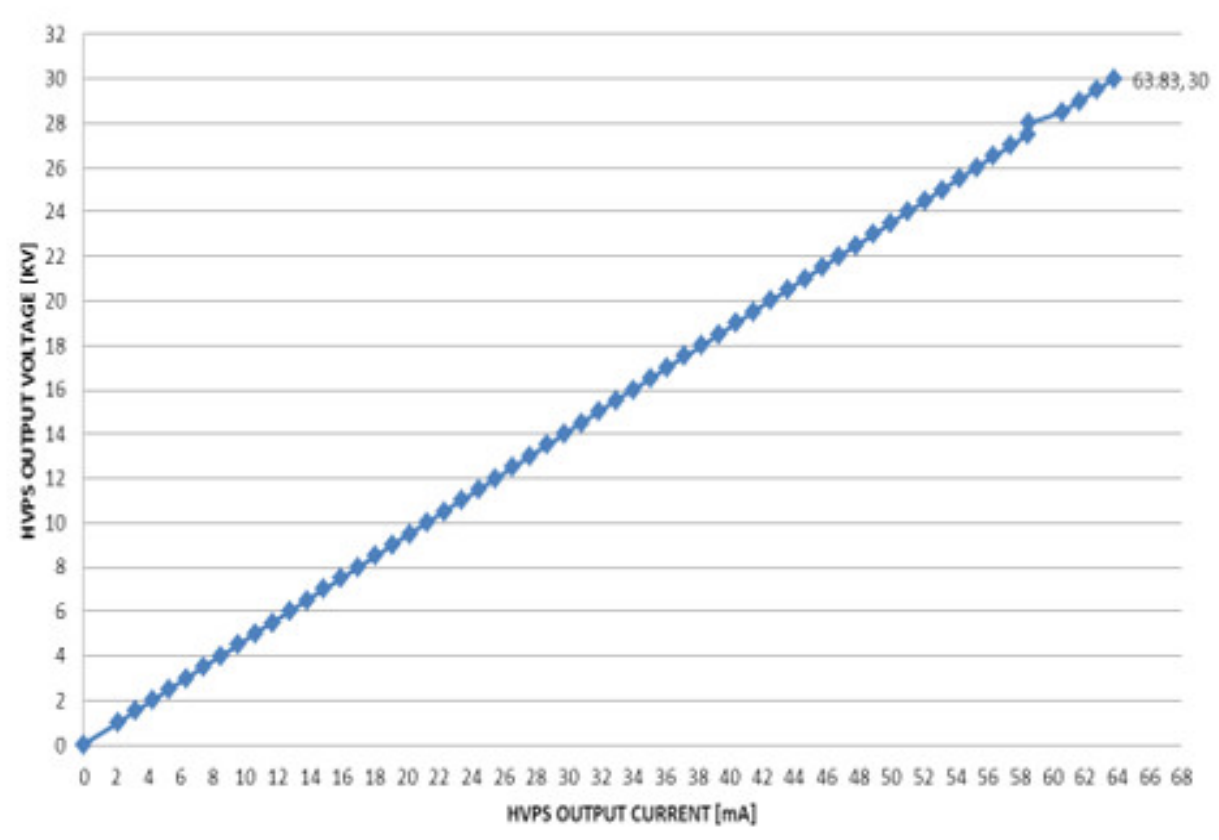

Figure 6: HVPS Graph showing output voltage against output current.

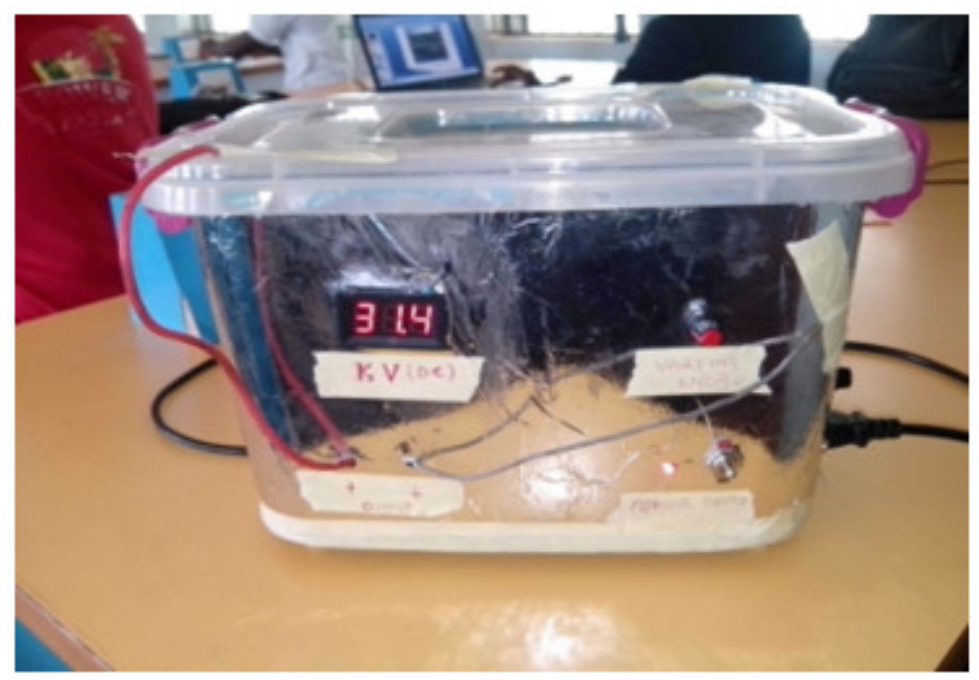

Plate 1: Fully constructed HVPS

Table 1: Specifications of the high voltage power supply

\begin{tabular}{ll}
\hline Output voltage range & $1000-32000 \mathrm{VDC}$ \\
\hline Maximum output current & $64 \mathrm{~mA}$ \\
Input voltage & $210-250 \mathrm{VAC}$ \\
Input current & $0.5-1 \mathrm{~A}$ \\
Device average power & $40-80$ watt. \\
\hline
\end{tabular}

Nig. J. Pure \& Appl. Sci. Vol. 33 (Issue 1): 3666-3673 


\section{Conclusions}

This work describes the process flow on the design of a variable high voltage DC power supply. A system hardware has been successfully fabricated and tested in the laboratory. The simulated and experimental results have been observed to be in agreement with each other and also with properties inherent in commercially available high voltage power supply. The biggest advantage to this design is this kind of high voltage DC power supply set is of simple control, low cost, and in relation to its output rating, it can be considered portable due to the careful selection of lightweight materials with robust and high efficiency. The developed equipment have been tested and found to be very useful for electrostatic applications such as electrospinning at the reduced cost of setting up an actual laboratory. The design is very easy for transportation to the sites and this device can be assembled in a matter of minutes. The beauty of this equipment is due to its high reliability, light weight, less expensive materials and its capability to produce different magnitude of high DC voltage. Finally, it should be highlighted that all the key component used in this design were sourced off the shelf from repurposing old and damaged electronic equipment's thereby contributing to saving the environment and ecology of our beloved planet earth.

\section{References}

Alayande, S. O., Bolarinwa, H. S., Akinsipo, B. O., Ofudje, A., Fasasi, A. Y., Ajao, J. A., Peleo, D. O. and Osinkolu, G. A. (2016). Study of surface modification of electrospun polyethylene oxide composite fibre. Fountain Journal of Natural and Applied Sciences, 5(2), 1-6.

Bolarinwa, H. S., Onuu, M. U., Fasasi, A. Y., Alayande, S. O., Animasahun, L. O., Abdulsalami, I. O., Fadodun, G. O. and Egunjobi, I. O. (2017). Determination of optical parameters of zinc oxide nanofibre deposited by electrospinning technique. Journal of Taibah University for Science, 11, 1245-1258.

Christophe. (2008). Power supplies: Practical Designs, Sydney: McGraw-Hill.

Cyril, W. (1993). Power Electronics. Lisbon: MccGraw Hill.

Dwivedi, C. K. and Daigavane, M. B. (2011). Multi-purpose low cost DC high voltage generator $(60 \mathrm{kV}$ output), using CockcroftWalton voltage multiplier circuit. International Journal of Science and Technology Education Research, 2(7), 109 119.

Fajingbesi, F. E., Midi, N. S. and Khan, S. (2017). A Novel Multilevel DC - AC Converter from Green Energy Power Generators Using StepSquare Waving and PWM Technique. IOP Conference Series: Materials Science and Engineering,210(1). https://doi.org/10.1088/ 1757-899X/210/1/012036

Forouzesh, M., Siwakoti, Y. P., Gorji, S. A., Blaabjerg, F. and Lehman, B. (2017). StepUp DC-DC converters: A comprehensive review of voltage-boosting techniques, topologies, and applications. IEEE Transactions on Power Electronics. https://doi.org/10.1109/TPEL.2017.265231 8

Garba, B. (2009). Design aand construction of 12 $\mathrm{kV}$ DC power supply. Bayero Journal of Pure and Applied Sciences, 2(2), 175-184.

Haridas, K., Khandelwal, S. and Das, A. (2016). AC to variable DC(buck and boost) modular multilevel converter using half bridge and full bridge cells. 2016 IEEE International Conference on Industrial Technology (ICIT), $257-$ 
262.https://doi.org/10.1109/ICIT.2016.7474 761

$\mathrm{Hu}$, C. (2009). Bipolar Transistor. Modern Semiconductor Devices for Integrated Page | 3673 Circuit, 291-324. https://doi.org/10.1002/9 781118014769.ch34

Hu, Z., Tan, W. and Kanoun, O. (2019). High Accuracy and Simultaneous Scanning AC Measurement Approach for TwoDimensional Resistive Sensor Arrays. IEEE Sensors Journal, 19(12), 4623-4628. https://doi.org/10.1109/JSEN.2019.2899135

Kuffel, E., Zaengl, W. S., and Kuffel, J. (2000). High voltage engineering fundamental. New York. https://doi.org/10.1016/b978-0-75063634-6.x5000-x.

Mansell, A. D. and Shen., J. (2002). Pulse converters in traction application. Power Engineering journal, 183.

Mazen, A.-S., Hussein, A., Ahdab, E. and Roshedy, R. (2000). High voltage engineering. New York: Marcel Dekker Inc.

Naidu, M. S. and Kamaraju, V. (2013). High voltage engineering (5th ed.). New Delhi: Tata McGraw-Hill Education Pvt Ltd.

Scapellati, C. (1995). High Voltage Power Supplies for Analytical Instrumentation. . Pittsburgh Conference.: Spellman High Voltage Electronics Corporation.

Yamamoto, I., Matsui, I. and Ueda., F. (2000). A power factor correction with voltage doubler rectifier. Industrial Electronics Society. Japan: 26th Annual Conference of the IEEE, Volume: 4.

Zhang, M., Llaser, N. L. and Devos, F. (2002). Experimental results of an optimized voltage Tripler. Paris: Orsay.
Rashad, M., Minhas, D. M., Ashraf, M. and Hussain, S. (2016). PFC topologies for AC to DC converters in DC micro-grid. 2016 18th Mediterranean Electrotechnical Conference (MELECON), (April), 1-6. https://doi.org/10.1109/MELCON.2016.749 5376 